\title{
Tectona grandis Capped Silver-Nanoparticle Material Effects on Microbial Strains Inducing Microbiologically Influenced Corrosion
}

\author{
Joshua Olusegun Okeniyi $\mathbb{D}^{1,2}$ Abimbola Patricia Idowu Popoola ${ }^{10}{ }^{2}$ \\ Modupe Elizabeth Ojewumi $\mathbb{D},{ }^{3}$ Elizabeth Toyin Okeniyi $(\mathbb{D}){ }^{4}$ \\ and Jacob Olumuyiwa Ikotun ${ }^{5}{ }^{5}$ \\ ${ }^{1}$ Mechanical Engineering Department, Covenant University, Ota, Nigeria \\ ${ }^{2}$ Chemical and Metallurgical Engineering Department, Tshwane University of Technology, Pretoria, South Africa \\ ${ }^{3}$ Chemical Engineering Department, Covenant University, Ota, Nigeria \\ ${ }^{4}$ Petroleum Engineering Department, Covenant University, Ota, Nigeria \\ ${ }^{5}$ Department of Civil Engineering and Building, Vaal University of Technology, Vanderbijlpark, South Africa
}

Correspondence should be addressed to Joshua Olusegun Okeniyi; joshua.okeniyi@covenantuniversity.edu.ng

Received 16 November 2017; Accepted 5 March 2018; Published 4 April 2018

Academic Editor: Javier M. Ochando-Pulido

Copyright (C) 2018 Joshua Olusegun Okeniyi et al. This is an open access article distributed under the Creative Commons Attribution License, which permits unrestricted use, distribution, and reproduction in any medium, provided the original work is properly cited.

\begin{abstract}
This paper investigates Tectona grandis capped silver nanoparticle material effects on the microbial strains inducing microbiologically influenced corrosion (MIC) of metals. Leaf-extract from Tectona grandis natural plant was used as a precursor for the synthesis of silver-nanoparticle material, which was characterised by a scanning electron microscopy having Energy Dispersion Spectroscopy (SEM + EDS) facility. Sensitivity and resistance studies by the synthesized Tectona grandis capped silver nanoparticle material on three Gram-positive and three Gram-negative, thus totalling six, MIC inducing microbial strains were then studied and compared with what was obtained from a control antibiotic chemical. Results showed that all the microbial strains studied were sensitive to the Tectona grandis capped silver nanoparticle materials whereas two strains of microbes, a Gram-positive and a Gram-negative strain, were resistant to the commercial antibiotic chemical. These results suggest positive prospects on Tectona grandis capped silver nanoparticle usage in corrosion control/protection applications on metallic materials for the microbial corrosion environment.
\end{abstract}

\section{Introduction}

Microbiologically influenced corrosion (MIC) can refer to changes in electrochemical reactions at the surface of a metallic material maintaining interface with system of microorganisms, conglomerated into biofilm, which induce corrosion process of the metallic material $[1,2]$. Many metallic materials, including stainless steel, and many environments, for example, domestic water, wastewater, marine, food processing, and oil and gas and industrial chemical, are susceptible to the material degradation of MIC [1-4]. This has made MIC related crises a cost-gulping phenomenon, in billions of dollars of direct cost, in many countries, while in the natural gas industries alone, MIC has accounted for about a third of corrosion failures [3,5]. Attachment of microbial strains unto metallic surfaces, leading to the formation of biofilm colony of microbes on the metal, has been identified as one of the major causative mechanism of microbiologically influenced corrosion (MIC) $[1,2,4]$. That the microbial attachment, the biofilm formation, and subsequent MIC induced corrosion damage of metallic material all occur on the material surface has been drawing research attention towards microbial and material surfaces interactions among the other conditions necessary for MIC attacks of metallic materials $[1,6,7]$. Microbes can refer to the entire evolutionary genus of microorganisms including bacteria, Archaea (methanogens), and Eukaryota (fungi), all of which are causative agents of MIC attacks on metallic materials [4]. However, motility of bacteria strains, especially the conveniently flagellated strains, enhances them with the 
special advantage of pioneering initial attachment to the metallic surface before attracting other secondary colonizers of microorganism, for forming MIC inducing biofilm [2, 7]. Once the mutual interactions of the colonies are established in the biofilm, resistance to MIC control approaches could be enhanced with consequence propagation of the corrosion degradation process. It is for this reason that attempts at making the initiation of MIC due to methods that could preclude or delay the initial attachment to the metallic surface are being opined as a corrosion-protection/control approach that will go a long way in MIC mitigation.

For instance, coating is a corrosion control method that can be applied to different types of metallic materials with suitable corrosion-protection additives [8] for which the use of nanotechnology based methods via nanoparticle usage is being proffered as a novel approach [9]. Notable research advances in this direction include the identification of the antimicrobial property of silver for its usage in the form of silver-nanoparticle dispersed in polymer or included in coating applications for metallic corrosion-protection and antibacterial resistance improvement $[10,11]$. Of pertinent relevance to the current discourse is the use, in [12], of silvernanoparticle material that had been synthesized from plants as reducing and capping agent for inhibition of both microbial growth and metallic corrosion in acidic chloride environment. Such synthesis of metallic nanoparticle via natural bioresource approach is known to offer benefits of environmental friendliness and ecocompatibility, especially due to the nonusage of toxic chemical for the synthesizing process.

Tectona grandis is a natural plant from which leaf-extract had been used successfully also for inhibiting mild steel and stainless steel corrosion in reported works [13, 14]. In addition to these, Tectona grandis leaf-extract has been employed recently for investigating the growth inhibition on MIC inducing microbes [15]. In spite of these, however, there is dearth of study in which the antimicrobial property from silver had been annexed with the green benefits that could be derivative from Tectona grandis usage as a precursor and capping agent for silver-nanoparticle synthesis. In contrast, extracts from many natural plants have been employed in studies for biologically mediated synthesis of silver-nanoparticle material [16-19]. Among these are leaves of Prunus persica by [16], Aloe vera by [17], and Azadirachta indica by [19]. In addition to these, the cited work in [18] detailed a review on the use of extracts from 40 plants, among which 27 are leaf-extracts, as a precursor for reducing silver from its compound to its nanoparticle. All these reports from the literature detailed antimicrobial effects of the biosynthesized silver nanoparticle, but none include use of Tectona grandis for the silver nanoparticle synthesis. Notable details of antimicrobial activity, from some of the cited works that also tested antimicrobial effect of the plant extract, for example, the report on Azadirachta indica in [19], include the indication that the plant extract usage alone resulted in "no zone" at inhibiting growth of the studied microbial strains. In sharp comparison, extracts from the fruit [20] and from the leaf [21] of Tectona grandis inhibited growth of different strains of microbes. Apart from these, Tectona grandis leafextract was also shown to be capable of improvement of antimicrobial potency when it was used in conjunction with tetracycline in [22]. These garner supports for the choice of Tectona grandis leaf-extract for use as a precursor for plant extract capped silver nanoparticle in this study.

More especially, motivation for the present study was drawn from the reported work in [22] wherein Tectona grandis leaf-extract was actually used for silver-nanoparticle synthesis but with antibacterial study conducted on only one Gram-positive (Staphylococcus aureus) and only one Gramnegative (Escherichia coli) strains of microbes. The positive results from that study indicate that more works need to be carried out for assessing the effectiveness of this bionanoparticle material on more types of microbes, especially those known to induce MIC. Such more types of microbes need to necessarily include Pseudomona aeruginosa (a flagellated, motile Gram-negative microbial strain), for instance, for this strain is known to usually pioneer attachment to metals for biofilm formation and eventual MIC attack on metallic materials $[2,7,23,24]$. Therefore the objective of this paper was to investigate effect of Tectona grandis capped silvernanoparticle on the inhibition of the growth of microbial strains inducing microbiologically influenced corrosion of metallic materials.

\section{Materials and Methods}

2.1. Tectona grandis Leaf-Extract Biosynthesis of SilverNanoparticle Material. Tectona grandis (T. grandis), Verbenaceae, was subjected to standard procedure detailed in [15] for obtaining pasty form of leaf-extract. This procedure includes drying in a well aerated room maintained at $20^{\circ} \mathrm{C}$ (by a 5-ton air-conditioning unit) and grinding it into small bits before wrapping in Whatman ${ }^{\circledR}$ filter paper for placing into a condenser-equipped soxhlet extractor utilizing $\mathrm{CH}_{3} \mathrm{OH}$ (methanol) for solvent medium. Out of the T. grandis leafextract paste obtained from the procedure detailed, $25 \mathrm{mg}$ was dissolved and made up to a volume of $1000 \mathrm{ml}$ using $0.1 \mathrm{M}$ $\mathrm{AgNO}_{3}$, that is, silver nitrate (Sigma Aldrich ${ }^{\circledR}$ ). As detailed in $[5,15]$, after $48 \mathrm{hrs}$, sample was obtained from the dissolution, which was then centrifuged at 3,500 rpm for 15 minutes in the Laboratory Centrifuge, Model SM-80-2 obtained from Surgifield ${ }^{\circledR}$ (England). The resultant supernatant was then poured out before the biosynthesized nanoparticle residue got transferred to a watch glass for air drying and afterwards collection in Eppendorf tubes. These were stored at room temperature for further use as the biosynthesized T. grandis capped silver nanoparticle in the study.

2.2. Characterisation of the Biosynthesized Silver-Nanoparticle Material. Sample from the biosynthesized T. grandis capped silver-nanoparticle was prepared and then characterised using a Pro X PHENOM ${ }^{\mathrm{TM}}$, Model 800-07334 (Phenomworld $^{\circledR}$, Netherlands) scanning electron microscopy and energy dispersive spectroscopy (SEM + EDS) instrument. For this characterisation, the sample was placed on a sample stub for loading onto the stage of the Quorum Sputter Coater, Model Q150R ES, obtained from Quorum Technologies Limited $^{\circledR}$ (England), and for coating the sample with gold $[5,15]$. This was followed by the removal of the sample stub, from the 


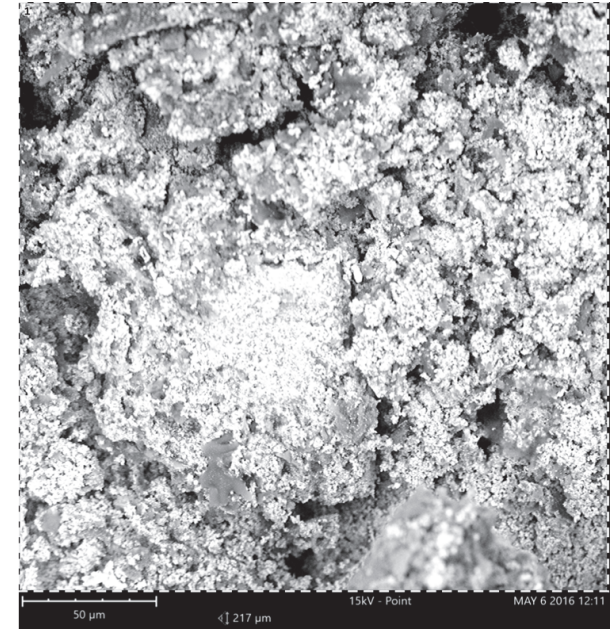

(a)

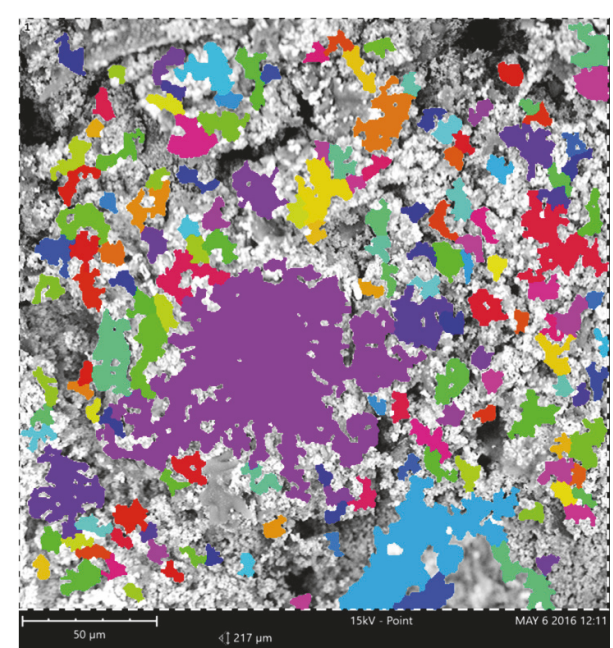

(b)

FIGURE 1: SEM + EDS analyses of the T. grandis capped silver-nanoparticle material. (a) Image from scanned electron microscope. (b) Clusters of particles colouring by ParticleMetric rendering of the scanned microscopic image.

coating instrument, for placing on standard sample holder mounted on the Pro X PHENOM, Model 800-07334 obtained from Phenomworld (Netherlands). On this instrument, the biosynthesized T. grandis capped silver-nanoparticle was subjected to the scanning electron microscopy and energy dispersive spectroscopy (SEM + EDS) analyses.

\subsection{Inhibition Study of MIC Inducing Microbial Strains.} Staphylococcus aureus (S. aureus) and Escherichia coli (E. coli) were used, respectively, as Gram-positive and Gramnegative microbial strains in this study. Reasons for choosing these microbial strains include the motivation to facilitate comparison of test-results from this study with what obtained from the previously cited work by other researchers [22]. In addition, however, Bacillus spp. and Micrococcus varians (M. varians) were included among the Gram-positive while Pseudomonas aeruginosa (P. aeruginosa) and Serratia spp. were among the Gram-negative microbial strain in the present study.

These isolates were obtained from the culture collection centre in the Biotechnology Unit of Department of Applied Biological Sciences, Covenant University, Ota, Ogun State, Nigeria, and were maintained on nutrient broth and incubated overnight at $37^{\circ} \mathrm{C}$ between 18 and 20 hrs $[25,26]$. From these cultures of microbial strains, $2 \mathrm{ml}$, of the microbes, was collected into sterile tube for making up with sterile distilled $\mathrm{H}_{2} \mathrm{O}$ until matching turbidity standard of $0.5 \%$ Mcfarland [27].

Each ensuing mixture of test-organisms was then used for seeding sterile nutrient agar plates, via the agar well diffusion method. Wells were bored into the seeded nutrient agar using $9 \mathrm{~mm}$ sterile cork borer. A gram by mass of the T. grandis capped silver nanoparticle was then dissolved and thoroughly mixed in $10 \mathrm{ml}$ of $\mathrm{C}_{2} \mathrm{H}_{6} \mathrm{OS}$ (Dimethyl sulfoxide; DMSO). From this dissolution, $0.2 \mathrm{ml}$ was obtained using sterile pipette, for dispersing into the well that had been bored onto the agar plate. This was followed by incubating the plates at $37^{\circ} \mathrm{C}$ for $24 \mathrm{hrs}$, before measuring, in $\mathrm{mm}$ unit, the zones of inhibition that resulted from this procedure [28].

For a positive control of antimicrobial effects, $10 \mu \mathrm{g}$ Gentamicin, from Abtek Biologicals Limited ${ }^{\mathrm{TM}}$ (Liverpool, UK), was utilized. The antibiotic chemical was used also, that is, just as the synthesized bionanoparticle material, in the seeded agar plates for the microbial growth inhibition study. This approach was to facilitate the comparison of the inhibition results obtained from the biosynthesized nanoparticle with that obtained from the antibiotic chemical usage.

\section{Results and Discussions}

3.1. Scanning-Electron-Microscopic (SEM) Analysis SEM. The image of the T. grandis capped silver-nanoparticle by the SEM instrument is shown in Figure 1(a) and analyses employing ParticleMetric $^{\circledR}$ rendering facility of the SEM instrument in Figure 1(b). Results from the ParticleMetric analysis indicated that for 157 particles the SEM facility could pick for the rendering in Figure 1(b), circle equivalent diameters, in $\mu \mathrm{m}$ unit, range from $($ median $=48.7$ : average $=57.5)$ to $($ median $=$ 8.26: average $=9.95)$. Figure $1(b)$ however depicted regions of uncoloured clusters that represent regions of particles beyond the identifiable range of the SEM system and indicate that nanoscale range of particles was obtained.

\subsection{Energy-Dispersive-Spectroscopic (EDS) Characterisation.} Results from the EDS characterisation of elemental constituents from the T. grandis capped silver nanoparticle are presented in Figure 2.

From the EDS characterisation in Figure 2, up to three spikes of silver (Ag), among the prominent spikes in the figure, could be identified. By this, it was established that silvernanoparticle material was obtained. The other spikes among which carbon, oxygen, and nitrogen are also prominent or 


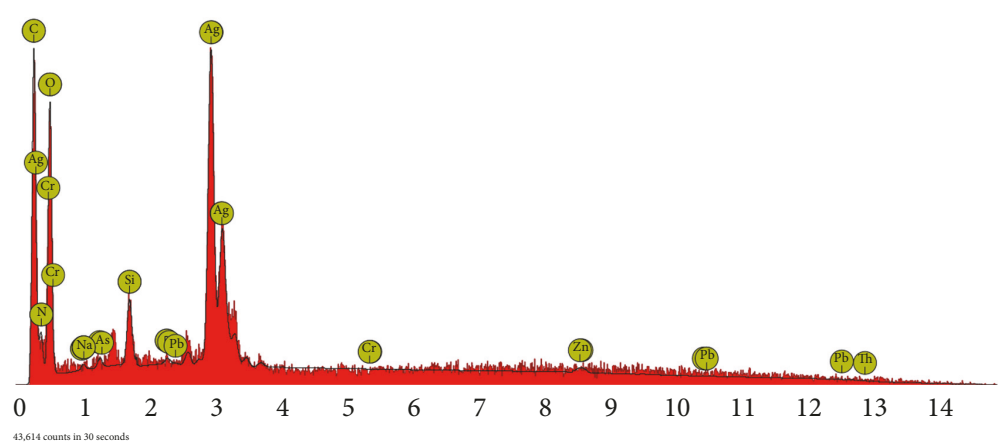

FIGURE 2: EDS characterisation of the bionanoparticle from the SEM facility.

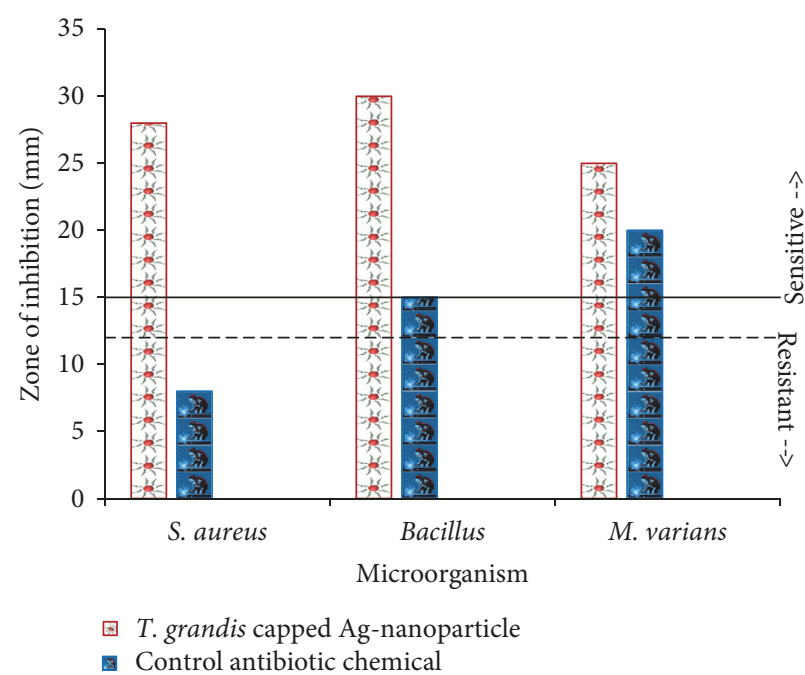

(a)

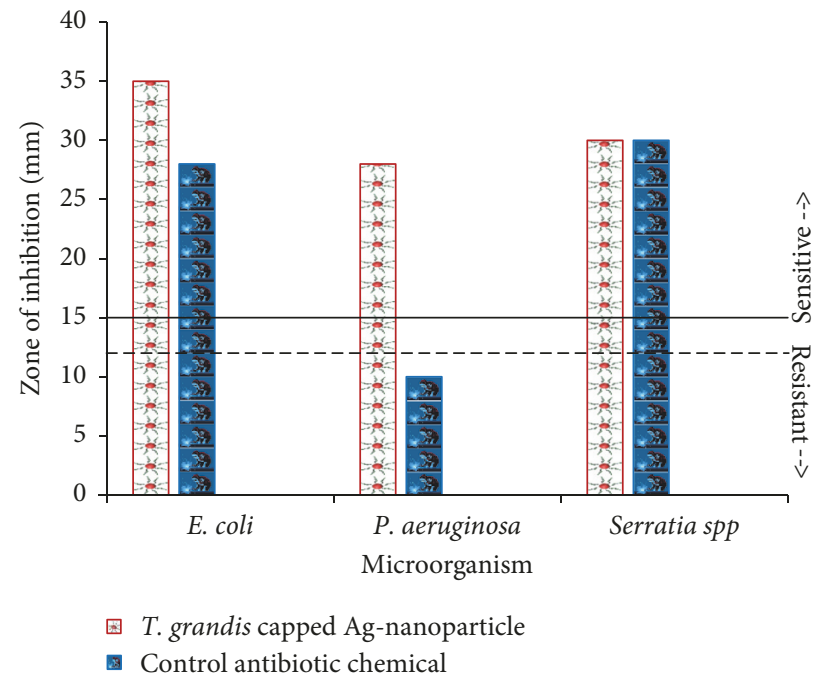

(b)

FIGURE 3: Growth inhibition effects by T. grandis capped silver-nanoparticle material on MIC inducing microbial strains. (a) Gram-positive microbial strains. (b) Gram-negative microbial strains.

prevalent corroborate elemental constituents of biocompatible compounds from the T. grandis leaf-extract as could be inferred from biochemical characterisation studies of other plant leaf-extracts in [29-33].

\subsection{T. grandis Capped Silver-Nanoparticle Effect on MIC} Inducing Microbial Strains Studied. Results of the growth inhibition effects by the T. grandis capped silver-nanoparticle on the studied MIC inducing microbial strains are presented in Figure 3, wherein Figure 3(a) depicts results from the Gram-positive and Figure 3(b) results from the Gramnegative microbial strains.

It could be noted that Figure 3 also includes linear plots of standard susceptibility criteria, as either sensitive or resistant, by the Gram-positive or Gram-negative microbes to the Gentamicin chemical, used as the antibiotic control for this study. These linear plots are for aiding direct interpretation of the zone of microbial growth inhibition obtained from the biosynthesized nanoparticle and the antibiotic control as per the susceptibility criteria from [34], according to microbial susceptibility interpretation for the standardized single-disc method [35]. From this, it could be deduced that all the three Gram-positive microbial strains for the study exhibited were sensitive to the $T$. grandis capped silver-nanoparticle material, by the zone of inhibition that was greater than $15 \mathrm{~mm}$ obtained for these microbes. Compared to this, only two of the Gram-positive microbial strains studied were sensitive to the Gentamicin (control antibiotic chemical), among which the Bacillus spp. just reached the $15 \mathrm{~mm}$ bar of zone of inhibition. The third Gram-positive strain of microbe for the study, S. aureus, was resistant to the Gentamicin control. In an almost similar manner, all the three Gramnegative strains of microbes for the study were sensitive to the $T$. grandis capped silver-nanoparticle material compared to only two, E. coli and Serratia spp., that were sensitive to the Gentamicin control antibiotic. The $P$. aeruginosa was resistant to the Gentamicin chemical, as per the set susceptibility criteria interpretation for the single-disc method in $[34,35]$.

\section{Conclusions}

By the results in the study, it is established that the $T$. grandis capped silver nanoparticle material, to which all the microbial strains studied were sensitive, outperformed 
the Gentamicin chemical on the inhibition of the growth of MIC inducing microbial strains studied. By this, it is opined that the T. grandis capped silver nanoparticle material could be suitable for use in MIC control applications for the corrosion-protection of metallic materials designed to operate in the MIC environment. However, further studies are recommended for investigating specific applications to which the biosynthesized nanoparticle material would be applied for situating antimicrobial effects for that condition of application.

\section{Conflicts of Interest}

The authors declare that there are no conflicts of interest regarding the publication of this paper.

\section{Acknowledgments}

The authors appreciate part-funding of this research by the following institutions: The National Research FoundationThe World Academy of Sciences, NRF-TWAS [Grant no. 105552], Covenant University Centre for Research Innovation and Discovery, CUCRID, Covenant University, Ota, Nigeria, and Vaal University of Technology, Vanderbijlpark, South Africa.

\section{References}

[1] M. A. Javed, W. C. Neil, P. R. Stoddart, and S. A. Wade, "Influence of carbon steel grade on the initial attachment of bacteria and microbiologically influenced corrosion," Biofouling, vol. 32, no. 1, pp. 109-122, 2016.

[2] J. Xia, C. Yang, D. Xu et al., "Laboratory investigation of the microbiologically influenced corrosion (MIC) resistance of a novel Cu-bearing 2205 duplex stainless steel in the presence of an aerobic marine Pseudomonas aeruginosa biofilm," Biofouling, vol. 31, no. 6, pp. 481-492, 2015.

[3] A. Y. Adesina, I. K. Aliyu, and F. M. Al-Abbas, "Microbiologically influenced corrosion (MIC) challenges in unconventional gas fields," in CORROSION, NACE International, Houston, TX, USA, 2015.

[4] B. J. Little and J. S. Lee, "Microbiologically influenced corrosion: An update," International Materials Reviews, vol. 59, no. 7, pp. 384-393, 2014.

[5] J. O. Okeniyi, G. S. John, T. F. Owoeye et al., "Effects of Dialium guineense Based Zinc Nanoparticle Material on the Inhibition of Microbes Inducing Microbiologically Influenced Corrosion," in Proceedings of the 3rd Pan American Materials Congress, pp. 21-31, Springer International Publishing, Cham, 2017.

[6] M. A. Javed, P. R. Stoddart, E. A. Palombo, S. L. McArthur, and S. A. Wade, "Inhibition or acceleration: Bacterial test media can determine the course of microbiologically influenced corrosion," Corrosion Science, vol. 86, pp. 149-158, 2014.

[7] H. Kanematsu, H. Ikigai, and M. Yoshitake, "Evaluation of various metallic coatings on steel to mitigate biofilm formation," International Journal of Molecular Sciences, vol. 10, no. 2, pp. 559-571, 2009.

[8] M. W. Kendig and R. G. Buchheit, "Corrosion inhibition of aluminum and aluminum alloys by soluble chromates, chromate coatings, and chromate-free coatings," Corrosion, vol. 59, no. 5, pp. 379-400, 2003.

[9] W. Fuerbeth, "New coatings for corrosion protection using nanoparticles or nanocapsules," in CORROSION, vol. 2015-, NACE International, Houston, Texas, USA, 2015.

[10] A. M. Atta, G. A. El-Mahdy, H. A. Al-Lohedan, and A. O. Ezzat, "Synthesis and application of hybrid polymer composites based on silver nanoparticles as corrosion protection for line pipe steel," Molecules, vol. 19, no. 5, pp. 6246-6262, 2014.

[11] R. Zeng, L. Liu, S. Li et al., "Self-assembled silane film and silver nanoparticles coating on magnesium alloys for corrosion resistance and antibacterial applications," Acta Metallurgica Sinica (English Letters), vol. 26, no. 6, pp. 681-686, 2013.

[12] A. S. Johnson, I. B. Obot, and U. S. Ukpong, "Green synthesis of silver nanoparticles using Artemisia annua and Sida acuta leaves extract and their antimicrobial, antioxidant and corrosion inhibition potentials," Journal of Materials and Environmental Science, vol. 5, no. 3, pp. 899-906, 2014.

[13] S. Kadapparambil, K. Yadav, M. Ramachandran, and N. Victoria Selvam, "Electrochemical investigation of the corrosion inhibition mechanism of Tectona grandis leaf extract for SS304 stainless steel in hydrochloric acid," Corrosion Reviews, vol. 35, no. 2, pp. 111-121, 2017.

[14] N. Kasthuri and M. Priy, "Thermodynamic studies for the corrosion inhibition of mild steel by Tectona grandis leaves," Journal of Applied Chemistry, vol. 4, no. 4, pp. 1-11, 2016.

[15] J. O. Okeniyi, O. A. Omotosho, M. A. Inyang et al., "Investigating inhibition of microbes inducing microbiologicallyinfluenced-corrosion by Tectona grandis based Fe-nanoparticle material," in Proceedings of the AIP Conference Proceedings, vol. 1814, AIP Publishing, 2017.

[16] R. Kumar, G. Ghoshal, A. Jain, and M. Goyal, "Rapid Green synthesis of silver nanoparticles (AgNPs) using (Prunus persica) plants extract: Exploring its antimicrobial and catalytic activities," Journal of Nanomedicine and Nanotechnology, vol. 8, no. 452, Article ID 1000452, 2017.

[17] P. Tippayawat, N. Phromviyo, P. Boueroy, and A. Chompoosor, "Green synthesis of silver nanoparticles in aloe vera plant extract prepared by a hydrothermal method and their synergistic antibacterial activity," Peer, vol. 2016, no. 10, Article ID e2589, 2016.

[18] S. Ahmed, M. Ahmad, B. L. Swami, and S. Ikram, "A review on plants extract mediated synthesis of silver nanoparticles for antimicrobial applications: a green expertise," Journal of Advanced Research, vol. 7, no. 1, pp. 17-28, 2016.

[19] S. Ahmed, M. Ahmad, B. L. Swami, and S. Ikram, "Green synthesis of silver nanoparticles using Azadirachta indica aqueous leaf extract," Journal of Radiation Research and Applied Sciences, vol. 9, no. 1, pp. 1-7, 2016.

[20] G. T. M. Bitchagno, L. S. Fonkeng, T. K. Kopa et al., "Antibacterial activity of ethanolic extract and compounds from fruits of Tectona grandis (Verbenaceae)," BMC Complementary \& Alternative Medicine, vol. 15, no. 1, p. 265, 2015.

[21] S. Lanka and Parimala, "Antimicrobial activities of Tectona grandis leaf and bark extracts," European Journal of Pharmaceutical and Medical Research, vol. 4, no. 12, pp. 245-248, 2017.

[22] R. Nalvothula, V. B. Nagati, R. Koyyati, R. Merugu, and P. R. M. Padigya, "Biogenic synthesis of silver nanoparticles using Tectona grandis leaf extract and evaluation of their antibacterial potential," International Journal of ChemTech Research, vol. 6, no. 1, pp. 293-298, 2014. 
[23] A. Abdolahi, E. Hamzah, Z. Ibrahim, and S. Hashim, "Microbially influenced corrosion of steels by Pseudomonas aeruginosa," Corrosion Reviews, vol. 32, no. 3-4, pp. 129-141, 2014.

[24] N. O. San, H. Nazir, and G. Dönmez, "Microbially influenced corrosion and inhibition of nickel-zinc and nickel-copper coatings by Pseudomonas aeruginosa," Corrosion Science, vol. 79, pp. 177-183, 2014.

[25] G. U. Akpan, G. Abah, and B. D. Akpan, "Correlation between microbial populations isolated from biofilms of oil pipelines and corrosion rates," The International Journal of Engineering and Science, vol. 2, no. 5, pp. 39-45, 2013.

[26] B. Mahesh and S. Satish, "Antimicrobial activity of some important medicinal plant against plant and human pathogens," World Journal of Agricultural Sciences, vol. 4, pp. 839-843, 2008.

[27] F. Olajubu, D. Ojo, I. Akpan, and S. Oluwalana, "Antimicrobial potential of Dialium guineense (Wild.) stem bark on some clinical isolates in Nigeria," International Journal of Applied and Basic Medical Research, vol. 2, no. 1, pp. 58-62, 2012.

[28] P. Logeswari, S. Silambarasan, and J. Abraham, "Synthesis of silver nanoparticles using plants extract and analysis of their antimicrobial property," Journal of Saudi Chemical Society, vol. 19, no. 3, pp. 311-317, 2015.

[29] J. O. Okeniyi, E. T. Okeniyi, O. O. Ogunlana, T. F. Owoeye, and O. E. Ogunlana, "Investigating biochemical constituents of Cymbopogon citratus leaf: Prospects on total corrosion of concrete steel-reinforcement in acidic-sulphate medium," in TMS 146th Annual Meeting \& Exhibition Supplemental Proceedings, pp. 341-351, Springer International Publishing, 2017.

[30] J. Okeniyi, C. Loto, and A. Popoola, "Effects of Phyllanthus muellerianus Leaf-Extract on Steel-Reinforcement Corrosion in 3.5\% NaCl-Immersed Concrete," Metals, vol. 6, no. 12, p. 255, 2016.

[31] J. O. Okeniyi, E. T. Okeniyi, and T. F. Owoeye, "Biocharacterisation of Solanum aethiopicum leaf: Prospect on steel-rebar total-corrosion in chloride-contaminatedenvironment," Progress in Industrial Ecology, an International Journal, vol. 10, no. 4, pp. 414-426, 2016.

[32] J. O. Okeniyi, O. O. Ogunlana, O. E. Ogunlana, T. F. Owoeye, and E. T. Okeniyi, "Biochemical characterisation of the leaf of Morinda lucida : Prospects for environmentally-friendly steelrebar corrosion-protection in aggressive medium," in TMS 2015 144th Annual Meeting \& Exhibition, pp. 637-644, Springer, Cham, 2015.

[33] J. O. Okeniyi, O. A. Omotosho, O. O. Ogunlana et al., "Investigating prospects of phyllanthus muellerianus as ecofriendly/sustainable material for reducing concrete steelreinforcement corrosion in industrial/microbial environment," Energy Procedia, vol. 74, pp. 1274-1281, 2015.

[34] R. Franklin and M. D. Cockerill III, "Performance standards for antimicrobial susceptibility testing; twenty-first informational supplement M100-S21," Clinical and Laboratory Standard Institute, vol. 31, pp. 68-80, 2001.

[35] A. W. Bauer, W. M. Kirby, J. C. Sherris, and M. Turck, "Antibiotic susceptibility testing by a standardized single disk method," American Journal of Clinical Pathology, vol. 45, no. 4, pp. 493496, 1966. 


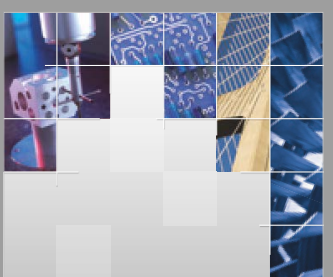

\section{Enfincering}
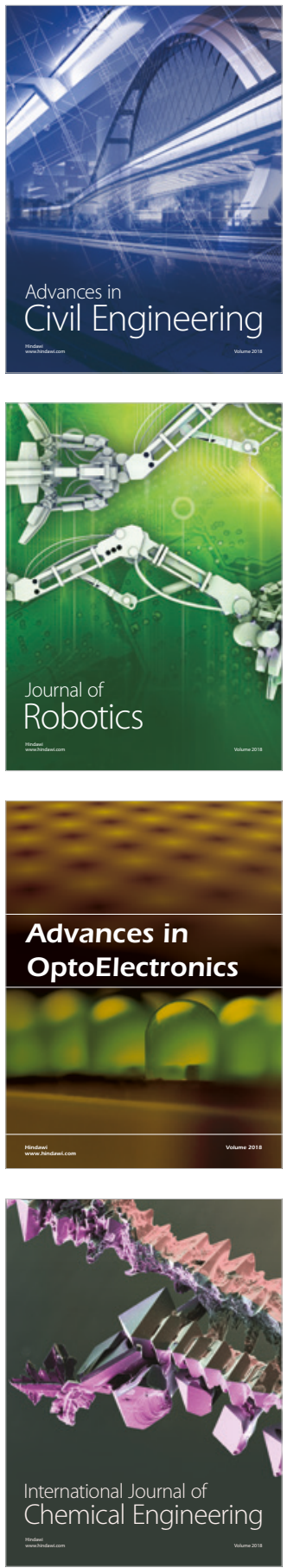

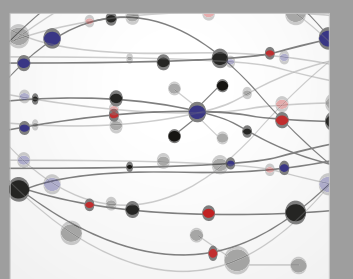

\section{Rotating \\ Machinery}

The Scientific World Journal

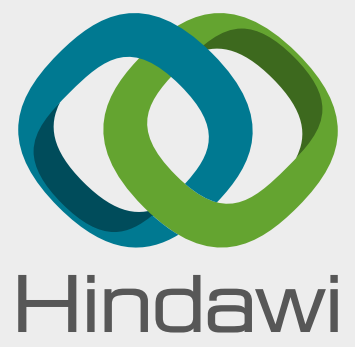

Submit your manuscripts at

www.hindawi.com
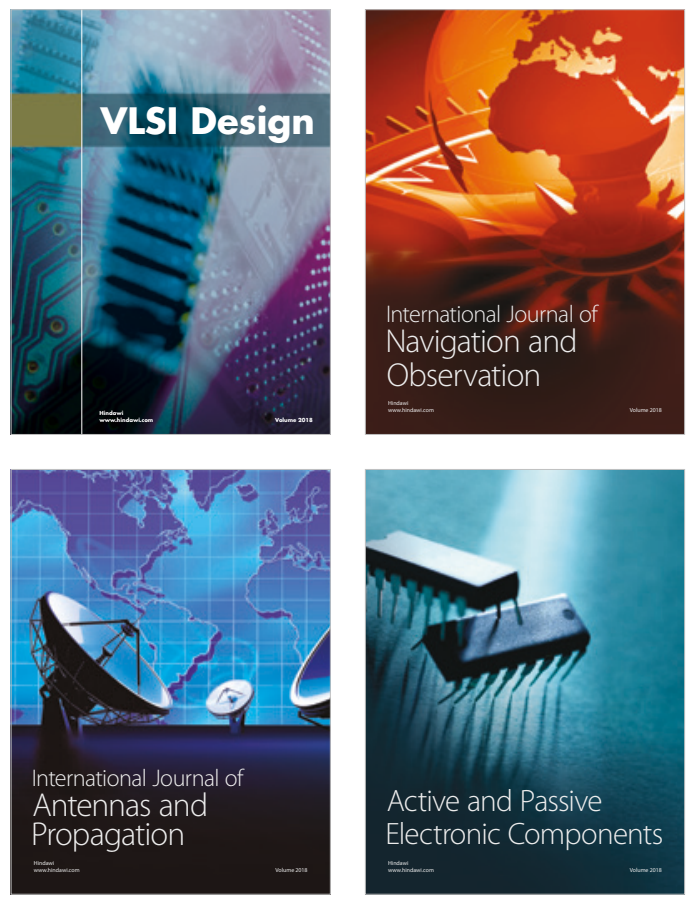
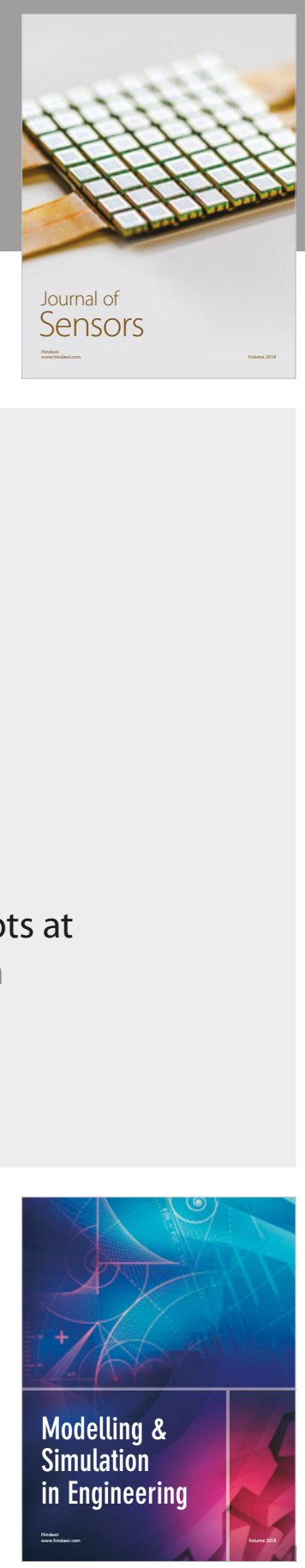

\section{Advances \\ Multimedia}
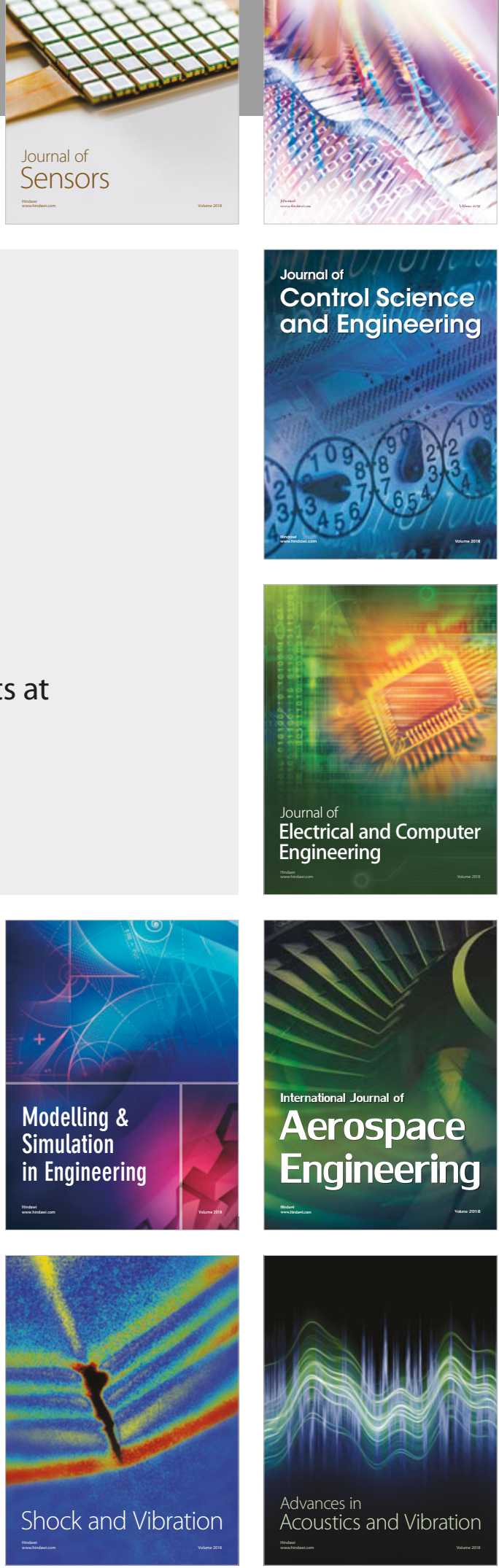